
H. Andel MD,*
G.S. Bayer MD, $\uparrow$
R. Ciovica MD, $\uparrow$
J. Monsivais MD,
M. Basco, $\ddagger$
M. Zimpfer $\mathrm{MD},{ }^{*} \$$
E. Turkof MD $\dagger$

\section{Depressive effect of isoflurane on motor evoked potentials in the Nubian goat}

Purpose: To determine the effect of isoflurane on motor evoked potentials (MEP) in a new animal model designed to verify the applicability of MEPs in brachial plexus surgery, and to compare the results with previous reports in other animals.

Methods: In seven goats, anesthesia was induced with $3 \mathrm{mg} \cdot \mathrm{kg}^{-1}$ ketamine iv and maintained with nitrous oxide $40 \%$ in oxygen and $2 \mu \mathrm{g} \cdot \mathrm{kg}^{-1} \cdot \mathrm{hr}^{-1}$ fentanyl $\mathrm{iv}$. The MEP were performed with two subcutaneous needle electrodes placed over the occiput (cathode) and the nasion (anode), with their plugs connected to the power output of a Digitimer D 180 electrical stimulator, connected to the trigger input of an electromyograph (model 8400, Cadwell Laboratories, Inc., Kennwick, Washington). Activation of the Digitimer caused central stimulation of the motor cortex, evoking baseline compound muscle action potentials (CMAPs) which were recorded from the left triceps muscle. Subsequently, isoflurane $2 \%$ was administered together with repeated central stimulation at 30 sec intervals.

Results: Onset of I- (indirect) waves increased from median I 5,8 msec to median 26,8 msec $P=0,0$ I 8 (latency increase ranged from: 9 to $11.5 \mathrm{msec}$ ), while peak-to-peak amplitudes decreased and subsequently disappeared. D- (direct) waves showed no latency increase, and finally disappeared as well. After disappearance of CMAPs, isoflurane administration was stopped and MEP repeated. The CMAPs reappeared (range: $210-360 \mathrm{sec}$ ) and regained initial peak-to-peak amplitudes and latencies.

Conclusion: These animal studies suggest that isoflurane should not be used during the recording of MEPs.

Objectif : Déterminer l'effet de l'isoflurane sur les potentiels évoqués moteurs (PEM) chez un nouveau modèle animal conçu pour vérifier l'applicabilité des PEM à l'opération du plexus brachial, et comparer les résultats avec ceux d'articles antérieurs chez d'autres animaux.

Méthode : L'anesthésie a été induite chez sept chèvres avec $3 \mathrm{mg} \cdot \mathrm{kg}^{-1}$ de kétamine iv et maintenue avec du protoxyde d'azote à $40 \%$ dans de l'oxygène et $2 \mu \mathrm{g} \mathrm{kg}^{-1} \cdot \mathrm{hr}^{-1}$ de fentanyl iv. Les PEM ont été réalisés avec deux aiguilles-électrodes sous-cutanées placées au niveau de l'occiput (cathode) et sur le nasion (anode) branchées à la borne d'entrée d'un électromyographe (modèle 8400, Cadwell Laboratories, Inc., Kennwick, Washington), leurs connecteurs étant reliés à la borne de sortie d'un stimulateur électrique Digitimer D 180. L'activation du Digitimer a provoqué une stimulation centrale du cortex moteur, évoquant les potentiels de base d'action musculaire combinée (PAMC) qui étaient enregistrés à partir des réactions du triceps gauche. Par la suite, l'isoflurane à $2 \%$ était administré en même temps qu'une stimulation centrale répétée à intervalles de $30 \mathrm{~s}$.

Résultats : L'installation des ondes I (indirectes) a montré un accroissement d'une médiane de I5,8 msec à une médiane de 26,8 msec $P=0,018$ (l'augmentation du temps de latence a varié de 9 à II,5 msec), tandis que les amplitudes entre les pics ont baissé, puis disparu. Les ondes D (directes) n'ont pas présenté d'accroissement du temps de latence et ont finalement disparu également. Après la disparition des PAMC, l'administration d'isoflurane a été stoppée et le PEM, répété. Les PAMC sont réapparus (intervalle : 210-360 s) et ont affiché de nouveau les amplitudes entre les pics et les temps de latence initiaux.

Conclusion : Ces études animales suggèrent que l'isoflurane ne doit pas être utilisé pendant l'enregistrement des PEM.

From the Departments of Plastic and Reconstructive Surgery and Ludwig Boltzmann Institute for Experimental Plastic Surgery, $\dagger$ Anesthesiology and Intensive Care, ${ }^{*}$ Ludwig Boltzmann Institute for Clinical Anesthesiology and Intensive Care, $\mathbb{\$}$ University of Vienna, Austria, Europe, and the Hand and Microsurgical Center and University of Texas at El Paso, $\ddagger$ El-Paso, Texas, USA.

Address correspondence to: Univ. Prof. Dr. Edvin Turkof, Abteilung für Plastische und Rekonstruktive Chirurgie, Universitätsklinik für Chirurgie, Allgemeines Krankenhaus der Stadt Wien, Währinger Gürtel 18 - 20, 1090 Wien, Austria, Europe. Phone: 43-1-40400/5620;

Fax: 43-1-40400/6988; E-mail: edvin-turkof@via.at Accepted for publication October 3, 1999

CAN J ANESTH 2000/47: 1/pp 81-86 
I N 1980, Merton and Morton ${ }^{1}$ described a method which allowed non-invasive stimulation of the entire motor cortex. The principle consisted of applying a high-voltage current between two surface electrodes placed on the scalp, hereby generating a three-dimensional electro-magnetical field able to penetrate the skull and to excite the precentral gyrus. This new technique enabled neurologists and neurosurgeons to verify the motor pathway of patients without the need for craniotomy.

In brachial plexus surgery, it is important to verify the functional status of anterior motor roots, because intradural lesions are difficult to recognize and lead to insufficient surgery if they remain undetected. ${ }^{2-3}$ An experimental study was set to verify the applicability of motor evoked potentials in brachial plexus surgery. ${ }^{2}$ The Nubian goat was selected as animal model because of the special anatomy of its cervical vertebral column which shows large interarcual spaces between the vertebra $\mathrm{C}_{5-6}$ and $\mathrm{C}_{6-7}{ }^{4-5}$ These wide openings are connected only by the ligamentum flavum, leaving the spinal cord unprotected from any bony structure at these two sites. ${ }^{4-5}$ This anatomical peculiarity enables exposure of the spinal cord without the need to perform hemilaminectomy within this restricted segment of the spinal vertebral column. ${ }^{2,4,5}$ Since the goat has never been used in MEP experiments, the choice of an appropriate anesthetic agent was required to perform this study. Isoflurane suppresses MEP in humans, ${ }^{6-8}$ rats, ${ }^{9,}{ }^{10}$ rabbits ${ }^{11}$ and cats. ${ }^{12,13}$ However, methods and results differed to a large extent in these studies. ${ }^{6-13}$ Therefore, we designed this animal experiment to investigate how the agent would act in a new animal model and to compare the findings obtained with results of similar studies.

Methods

Following animal research committee approval, three female and four male domestic adult Nubian goats (range of age: 2-7 yr), weighing between 32 and 61 $\mathrm{kg}$ (mean: $47.85 \mathrm{~kg}$ ) were selected for study (Table I). Goats were premedicated with $0.2 \mathrm{mg} \cdot \mathrm{kg}^{-1}$ xylazine and $0.5 \mathrm{mg}$ atropine $i \mathrm{~m}$. Anesthesia was induced 3 $\mathrm{mg} \cdot \mathrm{kg}^{-1}$ ketamine $i v$. After performing tracheotomy, the tracheas were intubated with a $7 \mathrm{~mm}$ cuffed tube and the lungs were ventilated (Mark 14 positive phase ventilator - Bird, Palm Springs Corporation, California) with an oxygen-nitrous oxide mixture (FI $\left.\mathrm{O}_{2}=0.6\right)$. The $\mathrm{PaCO}_{2}$ was maintained within normal limits $(4.6-5.3 \mathrm{kPa})$, as assessed by capnography and intermittent blood-gas analysis. Nitrous oxide was kept at $40 \%$ because this agent has a depressive effect on MEP at concentrations $>50 \% .^{14,15}$ Analgesia was maintained by $i v$ administration of $2 \mu \mathrm{g} \cdot \mathrm{kg}^{-1} \cdot \mathrm{hr}^{-1}$ fentanyl because of its minor effects on $\mathrm{MEP}^{15}$ and by subcutaneous administration of lidocaine $2 \%$ under the two stimulation electrodes. A polyethylene catheter was placed in the left femoral artery for blood-pressure recording and for blood sampling. Ringer's solution was infused at a rate of $3-5 \mathrm{ml} \cdot \mathrm{kg}^{-1}$ as required to keep hemodynamic variables within $10 \%$ of control values. In order to avoid excessive filling of the urinary bladder, suprapubic puncture and drainage were performed. Core temperature was registered with a rectal thermistor probe, and ECG was monitored with a 3-channel ECG-recorder (Hellige EK). Nasogastric suction was induced with a stomach tube. Statistical analysis was performed using the Wilcoxon Matched pairs signed ranks test, $P<0,05$ was considered to be significant.

\section{Experimental procedure}

The goats were positioned on their right flank. Two silver plate electrodes were glued with collodion on the shaved skin above the glabella (indifferent electrode) and the occiput (active electrode). The ground electrode was placed around the neck. A Digitimer D180 electrical stimulator was connected to the external trigger input of a model 8400 electromyograph (Cadwell Laboratories, Inc., Kennwick, Washington) and to the silver plate electrodes. Two disposable

TABLE I Data of seven goats in which isoflurane was administered at 2\%;. 'isoflurane+on': duration in seconds (left number) and amount of central stimulations (right number) following the administration of isoflurane until total disappearance of the CMAP. 'isoflurane+off: duration in seconds (left number) and number of central stimulations (right number) following omission of the agent until CMAP regained initial amplitude. 'Lat. incr.': Latency increase (msec).

\begin{tabular}{lllllllll}
\hline Goat & $\# 1$ & $\# 2$ & $\# 3$ & $\# 4$ & $\# 5$ & $\# 6$ & $\# 7$ & Mean \\
\hline Animal weight (kg) & 46 & 61 & 54 & 48 & 32 & 57 & 37 & 47.8 \\
Animal age (yr) & 2.5 & 4 & 3 & 6 & 3 & 4 & 3 & 3.6 \\
Sex & $\mathrm{f}$ & $\mathrm{f}$ & $\mathrm{m}$ & $\mathrm{m}$ & $\mathrm{m}$ & $\mathrm{m}$ & $\mathrm{f}$ & $/$ \\
isoflurane ON (sec/stimulations) & $90 / 3$ & $120 / 4$ & $90 / 3$ & $90 / 3$ & $60 / 2$ & $90 / 3$ & $60 / 2$ & $85 / 2.8$ \\
isoflurane OFF (sec/stimulations) & $360 / 12$ & $300 / 10$ & $330 / 11$ & $360 / 12$ & $240 / 8$ & $330 / 11$ & $210 / 7$ & $304 / 10$ \\
Lat. incr. isoflurane (msec) & 11 & 9.7 & 10.8 & 9.2 & 13 & 11.4 & 12.5 & 11.1 \\
\hline
\end{tabular}




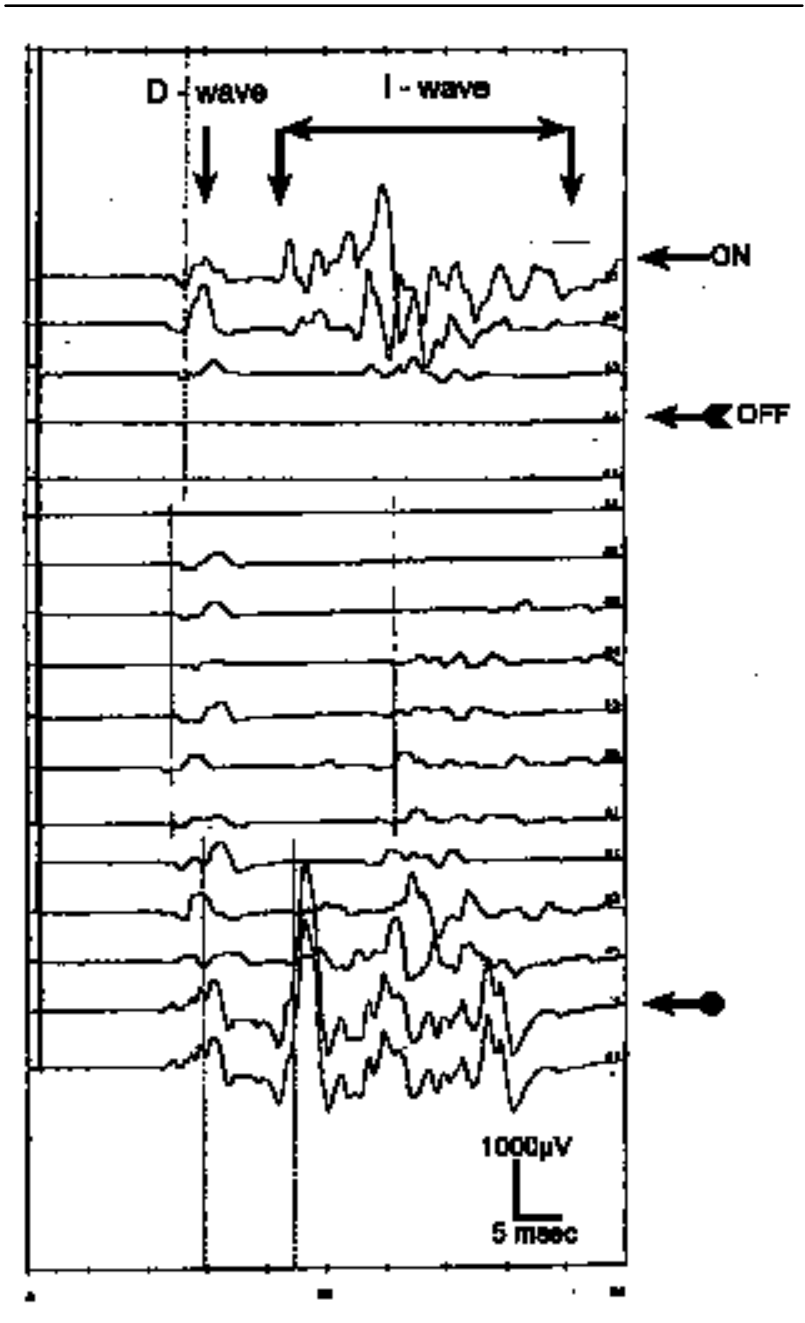

FIGURE: CMAP from the anterior limb left triceps muscle after central stimulation in goat \#4 with isoflurane $2 \%$; first line: before administration of the agent;

" ON": beginning of administration;

" I OFF": omission of the agent.

“ ": amplitudes regained initial values. Interval between each stimuation: $30 \mathrm{sec}$.

Time: $5 \mathrm{msec} /$ division, amplification: $1000 \mu \mathrm{V} /$ division)

unipolar EMG needle electrodes were placed approximately $3 \mathrm{~cm}$ apart in the lateral caput of the triceps muscle of the left anterior limb and connected to the preamplifier of the electromyograph. Central stimulation was performed with 750 volts, and compound muscle action potentials (CMAPs) were recorded following digitalization by the inbuilt analog-digital-converter of the electromyograph (settings: time: $5 \mathrm{msec}$ per division, amplification: $1000 \mu \mathrm{V}$ per division
(Figure). After recording of the baseline CMAP, isoflurane was administered at $2 \%$ (Figure). Central stimulation was repeated at intervals of $30 \mathrm{sec}$. If the CMAP disappeared, isoflurane was turned off (Figure) and central stimulation was repeated at the same intervals until CMAP reappeared and returned to initial values (Table I, Figure), as before the administration of the volatile agent.

Results

At a stimulus intensity of 750 volts, both "D" waves (the first wave elicited if the membrane potential of the initial segment in the white matter is depolarized before the stimulus, a phenomenon that occurs if the stimulus intensity is sufficiently high) and "I" waves (a series of waves which are elicited by excitation of the deep layers of the grey matter - Figure 1) were elicited. ${ }^{14}$ In all seven goats, the application of isoflurane at $2 \%$ caused an initial attenuation of amplitudes of both "I" and "D" waves which led to disappearance of CMAPs. The mean time until disappearance of the CMAPs was $85 \mathrm{sec}$ (range: 60-120 sec, or 2-4 stimuli, Table I). After withdrawal of isoflurane, a mean time of $304 \mathrm{sec}$ passed until amplitudes returned to initial values (range: $210-360 \mathrm{sec}$, or 7-12 stimuli, Table I). Together with the decrease or disappearance respectively of amplitudes, an increase in onset time from median $15,8 \mathrm{msec}$ to $26,8 \mathrm{msec} P=0,018$ was observed (latency increased to mean: 11.1, range: 9.213 msec, Table I), however this effect was restricted to I-waves alone: the latency of $\mathrm{D}$-waves remained stable $^{14}$ (Figure).

\section{Discussion}

The present study was designed to determine the depressive effect of isoflurane on CMAP in a new animal model, the Nubian goat, and to compare the results with previous reports in other animals. We used isoflurane at $2 \%$ because three goats showed signs of pain and awakening in concentrations $<1.5 \%$. We did not examine the effect of incremental concentration increases, much of which has all ready been reported. ${ }^{6-11,13}$ Nitrous oxide and fentanyl were used in combination with isoflurane, and care was taken to exclude their additional depressive effects by keeping their concentrations below critical values. ${ }^{15,16}$

Our results confirmed the findings of similar studies: as with the other reports, ${ }^{6-13}$ we observed dose- and time- dependent effects on amplitudes and latencies of MEP under isoflurane anesthesia. However, a comparison cannot be made without taking into consideration several methodological differences among the studies mentioned. ${ }^{6-13}$ These differences consist of: A) the 
model (several species, humans), B) the different concentrations of isoflurane, $\mathrm{C}$ ) the use of nitrous oxide in concentrations which contribute to the depressive effect of isoflurane, D) the stimulation method and stimulation site (magnetic or electrical, transcranial or directly after craniotomy), E) the recording site (spinal cord, muscles) and, as a result, F) the large variety of the described results. ${ }^{6-13}$ (Table II)

A) The choice of a convenient model is mostly a matter of availability and price. In our case, however, the special anatomy of the cervical vertebral column ${ }^{5}$ led us to use the goat because no other animal model commonly used in medical experiments enables such non-traumatic exposure of spinal roots. Furthermore, when the size of the model is important for the goal of the study, the goat should be considered because its costs are lower than sheep or monkeys.

B) Most authors tested the effect of isoflurane in incremental concentration steps. ${ }^{6-11,13}$ But the range of concentrations differs remarkably: $0.25 \%$ - $1 \%$ studied Yamada et al., ${ }^{13}$ while Schmidt et al. ${ }^{9}$ tested from
0.5 to $3 \%$, the others remained between these values. ${ }^{6,7,9-11}$ In contrast, $\operatorname{Toda}^{12}$ investigated a single concentration, an approach similar to our study, in which $2 \%$ were used throughout the experiment.

C) Four authors added nitrous oxide to isoflurane at concentrations $>50 \% .{ }^{6-8,12}$ However, nitrous oxide has a depressive effect on MEP at these concentrations. ${ }^{12,15,16}$

D) Five authors and ourselves used electrical stimulation. 6,7,9-11 Others chose magnetic stimulation. $8,12,13$ Amplitudes of MEP are higher using electrical stimulation than magnetic stimulation. ${ }^{17}$ Electrical, but not magnetic stimulation is painful. Therefore, one may expect amplitudes to be more resistant to isoflurane and analgesia to be increased when MEP is performed using electrical stimulation. The different characteristics of electrical and magnetic stimulation are probably the cause of the monophasic CMAPs in Yamada's report 13 (magnetic stimulus), while, in contrast, Haghigi's ${ }^{9}, 10$ (electric stimulus) and our recordings were polyphasic. For the same reason, Toda 12 - (magnetic stimulus)

TABLE II Reports of effect of isoflurane on Motor Evoked Potentials. Note the differences among animal models, concentrations of isoflurane, the use of other agents in combination with isoflurane, the stimulation sites and stimulation methods, the recording sites and results.

\begin{tabular}{|c|c|c|c|c|c|c|c|c|c|c|}
\hline & & $\begin{array}{l}\text { Hagghigi } \\
\text { et al. }{ }^{7} \\
1990\end{array}$ & $\begin{array}{l}\text { Hagghigi } \\
\text { et al. } \\
1990\end{array}$ & $\begin{array}{l}\text { Calencie } \\
\text { et al. }{ }^{4} \\
1991\end{array}$ & $\begin{array}{l}\text { Schmidt } \\
\text { et al. }{ }^{6} \\
1992\end{array}$ & $\begin{array}{l}\text { Hicks } \\
\text { et al. } \\
1992\end{array}$ & $\begin{array}{l}\text { Zentner } \\
\text { et al. }{ }^{9} \\
1992\end{array}$ & $\begin{array}{l}\text { Todalo } \\
1992\end{array}$ & $\begin{array}{l}\text { Yamada } \\
\text { et al. }{ }^{11} \\
1993\end{array}$ & $\begin{array}{l}\text { Andel } \\
\text { et al. } \\
1998\end{array}$ \\
\hline A & Species & rat & rat & human & human & human & rabbit & cat & cat & goat \\
\hline B & Concn \% & $0.2-1.5$ & $0.2-1.5$ & $0.4-1$ & $0.5-3$ & $0.5-2$ & $0.36-2.19$ & 1.5 & $0.25-1$ & 2 \\
\hline $\begin{array}{l}\mathrm{C} \\
40\end{array}$ & $\begin{array}{l}\text { Use of nitrous } \\
\%\end{array}$ & yes & \multicolumn{2}{|c|}{$33 \%, 50 \%, 66 \%$} & $60 \%$ & $79 \%$ (not in & $70 \%$ & no & $67 \%$ & no \\
\hline $\mathrm{D}$ & $\begin{array}{l}\text { Stimulation } \\
\text { site }\end{array}$ & motor cortex & motor cortex & motor cortex & motor cortex & motor cortex & motor cortex & $\begin{array}{l}\text { motor cortex } \\
\text { spinal cord }\end{array}$ & motor cortex & motor cortex \\
\hline $\mathrm{E}$ & Recording site & muscle & muscle & muscle & muscle & spinal cord & $\begin{array}{l}\text { spinal cord } \\
\text { and muscle }\end{array}$ & $\begin{array}{l}\text { spinal cord } \\
\text { and muscle }\end{array}$ & $\begin{array}{l}\text { spinal cord } \\
\text { muscle }\end{array}$ & muscle \\
\hline & $\begin{array}{l}\text { Differentiation } \\
\text { between D and } \\
\text { I waves \& } \\
\text { results }\end{array}$ & no & no & no & no & $\begin{array}{l}\text { yes } \\
\text { attenuation of } \\
\text { both } \mathrm{D} \text { and I } \\
\text { waves above } \\
0.5 \%\end{array}$ & no & $\begin{array}{l}\text { yes } \\
50 \% \text { attenua- } \\
\text { tion of I-waves } \\
\text { at } 1.5 \%, D \text { - } \\
\text { waves stable }\end{array}$ & $\begin{array}{l}\text { yes } \\
\text { slight attenua- } \\
\text { tion of I-wave } \\
\text { amplitudes }\end{array}$ & $\begin{array}{l}\text { yes } \\
\text { attenuation of } \\
\text { both I and D } \\
\text { waves, D } \\
\text { waves more } \\
\text { resistent }\end{array}$ \\
\hline $\mathrm{F}$ & $\begin{array}{l}\text { Attenuation } \\
\text { of amplitudes } \\
\&\end{array}$ & $\begin{array}{l}\text { amplitudes } \\
\text { decrease at } \\
0.4 \% \text { and dis- }\end{array}$ & $\begin{array}{l}\text { amplitudes } \\
\text { decrease at } \\
0.4 \% \text { and dis- }\end{array}$ & $\begin{array}{l}\text { amplitudes } \\
\text { decrease at } \\
0.4 \%\end{array}$ & $\begin{array}{l}\text { amplitudes } \\
\text { decrease } \\
\text { above } 0.5 \%\end{array}$ & $\begin{array}{l}\text { amplitudes } \\
\text { decrease, but } \\
\text { remain record- }\end{array}$ & $\begin{array}{l}\text { amplitudes } \\
\text { decrease above } \\
0.25 \text { MAC an }\end{array}$ & $\begin{array}{l}\text { amplitudes of } \\
\text { eMAP's de- } \\
\text { ad }\end{array}$ & $\begin{array}{l}\text { amplitudes de- } \\
\text { crease and lat- } \\
\text { crease to } 30 \%\end{array}$ & $\begin{array}{l}\text { amplitudes } \\
\text { decrease and } \\
\text { encies increase }\end{array}$ \\
\hline & $\begin{array}{l}\text { ncies in- } \\
\text { increase of } \\
\text { onset latencies }\end{array}$ & appear at $1 \%$ & appear at $1 \%$ & & $\begin{array}{l}\text { and disappear } \\
\text { above at } 1 \%\end{array}$ & $\begin{array}{l}\text { able even at } \\
2 \%\end{array}$ & $\begin{array}{l}\text { disappear at } \\
1 \%\end{array}$ & $\begin{array}{l}\text { on spinal } \\
\text { stimulation, } \\
\text { disappear on } \\
\text { central stimu- } \\
\text { lation }\end{array}$ & $\begin{array}{l}\text { above } 0.25 \% \\
\text { amplitudes are } \\
\text { recordable up } \\
\text { to } 1 \%\end{array}$ & crease at $2 \%$ \\
\hline
\end{tabular}


could keep isoflurane at a relatively low concentration of $1.5 \%$ without awakening the cats, compared with $2 \%$ used in our study (electric stimulus).

E) Five authors ${ }^{5,7-10,12}$ recorded the MEPs, as we did, from muscles alone. One author recorded the MEPs from the spinal cord alone, ${ }^{7}$ and two used two recording sites -the spinal cord and the muscles. ${ }^{11,13}$ This distinction is necessary because recordings from the spinal cord are more resistant to the influence of anesthetic agents than are CMAPs ${ }^{11,13}$ (Table II). This is due to: 1) the distance between stimulation and recording sites is shorter, thus reducing the biological resistance and 2) the recording occurs proximally from the synapses of the spinal roots. Therefore, the results of several apparently similar reports ${ }^{6-13}$ cannot be compared simply.

F) Only three authors ${ }^{7}, 12,13$ mentioned the different sensitivity of D and I waves to isoflurane. Yamada $e t a l . .^{13}$ observed only D-waves on epidural recordings. The CMAPs described in his study showed I-waves alone, probably due to the less intense stimulus of the magnetic coil. In our study, D-waves could be observed and were more resistant than I-waves. An increase of Dwaves-latencies did not occur and peak-to-peak amplitudes showed a delayed decrease (Figure 1), with complete disappearance at $2 \%$. Toda ${ }^{12}$ observed the amplitudes of $\mathrm{D}$-waves to be stable at $1.5 \%$ on spinal stimulation and, similar to our study, to disappear on central stimulation (Table II). Hicks et al. observed D and I waves on epidural recordings, with both waves remaining recordable at concentrations up to $2 \%$. These $^{7}$ results, together with Yamada's ${ }^{13}$ findings, emphasize the higher resistance of spinal potentials towards depressive agents when compared to CMAPs.

In summary, we demonstrated that the nubian goat shows similar sensitivity to the depressive effect of isoflurane on MEP as other animals ${ }^{9-13}$ and humans. ${ }^{6-8}$ The I-waves showed a rapid attenuation until complete disappearance of peak-to-peak amplitudes and an increase of latencies, wave-forms being constantly polyphasic. The $\mathrm{D}$-waves of CMAPSs diminished slow ly until disappearance under isoflurane anesthesia at $2 \%$, but their latencies, remained stable. For clinical application, our observations suggest that, in accordance with previous reports, one should carefully design anaesthesia for brachial plexus surgery if intraoperative monitoring is to be performed in order to avoid an incompatible combination of agents.

We conclude that isoflurane is an unsuitable anesthetic agent when MEPs are to be obtained in the Nubian goat.
Acknowledgments

The authors wish to thank Dr. McKee from El - Paso who allowed us to fulfill this study in his veterinarian clinic.

The study was supported by the scientific fund from the Medical University of Vienna, Zeneca Inc., Vienna, Novartis Inc., Vienna, Glaxo Inc., Vienna, Smith-Kline-Beecham Inc., Vienna, and the Ludwig Boltzmann Institute for Experimental Plastic Surgery, Vienna, Austria.

\section{References}

1 Merton PA, Morton HB. Stimulation of the cerebral cortex in the intact human subject. Nature 1980; 285: 227.

2 Turkof E, Monsivais J, Dechtyar I, Bellolo H, Millesi H, Mayr N. Motor evoked potential as a reliable method to verify the conductivity of anterior spinal roots in brachial plexus surgery: an experimental study on goats. J Reconstr Microsurg 1995; 11: 357-62.

3 Turkof E, Millesi H, Turkof R, Pfundner P, Mayr N. Intraoperative electroneurodiagnostics (transcranial electrical motor evoked potentials) to evaluate the functional status of anterior spinal roots and spinal nerves during brachial plexus surgery. Plast Reconstr Surg 1997; 99: 1632-41.

4 Turkof E, Monsivais J, Mayer N, Millesi $H$ The goat: a viable experimental anatomical model for testing spinal root conductivity with SSEP, MEP without laminectomy. Abstracts of the 11th Congress of the International Microsurgical Society; Rhodes, Greece, 1992; 51.

5 Turkof E, Bellolo H, Monsivais J. The anatomy of the vertebral column of the nubian goat: a peculiarity of the arcus vertebrae C5, C6 and C7 forming large spatia interarcualia. Can J Vet Res 1994; 58: 156.

6 Calancie B, Klose KJ, Baier S, Green BA Isofluraneinduced attenuation of motor evoked potentials caused by electrical motor cortex stimulation during surgery. J Neurosurg 1991; 74: 897-904.

7 Hicks RG, Woodforth IJ, Crawford MR, Stephen JPH, Burke DJ. Some effects of isoflurane on I waves of the motor evoked potential. Br J Anaesth 1992; 69: 130-6.

8 Schmid UD, Boll J, Liechti S, Schmid J, Hess CW. Influence of some anesthetic agents on muscle responses to transcranial magnetic cortex stimulation: a pilot study in humans. Neurosurgery 1992; 30: 85-92.

9 Haghighi SS, Green KD, Oro JJ, Drake RK, Kracke GR Depressive effect of isoflurane anesthesia on motor evoked potentials. Neurosurgery 1990; 26: 993-7.

10 Haghighi SS, Madsen R, Green KD, Oro JJ, Kracke GR Suppression of motor evoked potentials by inhalation anesthetics. J Neurosurg Anesthesiol 1990; 2: 73-8. 
11 Zentner J, Kiss I, Ebner A Influence of anesthetics nitrous oxide in particular - on electromyographic response evoked by transcranial electrical stimulation of the cortex. Neurosurgery 1989; 24: 253-6.

12 Toda $\Upsilon$. The effect of anesthetic agents on descending spinal cord evoked potential and the compound muscle action potentials elicited by stimuation at the cerebral motor cortex and the spinal cord. Japanese Journal of the Orthopaedic Association 1992; 66: 279-90.

13 ramada H, Transfeldt EE, Tamaki T, Torres F, Iaizzo $P A$. The effects of volatile anesthetics on the relative amplitudes and latencies of spinal and mucsle potentials evoked by trancranial magnetic stimulation. Spine 1994; 19: 1512-7.

14 Amassian VE, Stewart M, Quirk GJ, Rosenthal JL. Physiological basis of motor effects of a transient stimulus to cerebral cortex. Neurosurgery 1987; 20: 74-93.

15 Jellinek D, Platt M, Jewkes D, Symon L. Effects of nitrous oxide on motor evoked potentials recorded from skeletal muscle in patients under total anesthesia with intravenously administered propofol. Neurosurgery 1991; 29: 558-62.

16 Zentner J, Albrecht T, Heuser D. Influence of halothane, enflurane and isoflurane on motor evoked potentials. Neurosurgery 1992; 31: 298-305.

17 Rothwell JC, Day BL, Thompson PD, Dick JPR, Marsden CD. Some experiences of techniques for stimulation of the human cerebral motor cortex through the scalp. Neurosurgery 1987; 20: 156-63. 